\title{
Cuerpo y alma. Memoria y subjetividades en el proceso creativo teatral
}

\author{
Body and Soul. Memory and Subjectivities \\ in the Creative Theater Process
}

Magda García

\section{DOI 10.15517/es.v81i1.47287}

(c) (1) () Esta obra está bajo una licencia Creative Commons 
Reflexiones

\title{
Cuerpo y alma. Memoria y subjetividades en el proceso creativo teatral \\ Body and Soul. Memory and Subjectivities in the Creative Theater Process
}

\author{
Magda García ${ }^{1}$ \\ Universidad Rafael Landívar \\ Ciudad de Guatemala, Guatemala
}

Recibido: 03 de febrero de 2020 Aprobado: 24 de junio de 2020

\section{Introducción}

A finales de 2017, me adentré en un proceso investigativo sobre el proceso creativo teatral desde la perspectiva de la experiencia y del cuerpo como fuentes de construcción de conocimiento. En estudios realizados con anterioridad, me centré en la observación de procesos creativos de colectivos artísticos en las disciplinas de teatro, danza y artes visuales con el fin de reflexionar sobre el proceso que precede a la manifestación de las obras artísticas, desde las etapas tempranas de improvisación hasta la concreción de las mismas en el montaje escénico y la exposición visual. Con ello, establecí la existencia de aspectos transformadores individuales y colectivos durante las distintas fases de la creación. Como un seguimiento a esto, me interesó vivir en carne propia esta experiencia y escribir un monólogo de corte autobiográfico, de manera que el proceso trascendiera lo intelectual para atravesar mi cuerpo y, desde allí, profundizar en las potencialidades transformadoras del trabajo creativo artístico.

1 Doctora en Historia de América Latina por la Universidad Pablo de Olavide, Sevilla, España. Académica-investigadora en el Instituto de Investigación y Proyección sobre Diversidad Sociocultural e Interculturalidad de la Universidad Rafael Landívar. ORCID: 0000-0002-7211-1434. Correo electrónico: magarciav@url.edu.gt 
Sobre estos intereses, conversé con Patricia Orantes², quien en ese momento era directora del Laboratorio teatral de la Universidad Rafael Landívar de Guatemala. Surgió entonces la posibilidad de trabajar en conjunto y acordamos que ella dirigiría todo mi proceso creativo, desde cero, para crear una obra teatral inédita. Esta conversación con Patricia abrió una gran oportunidad para ya no ser solamente observadora del proceso creativo, sino vivirlo en carne propia; ser yo misma mi sujeto de estudio, ahora prestando mi cuerpo y mi emocionalidad entera a un proceso creativo tanto en la dramaturgia como en la interpretación de un monólogo.

Esto representó una nueva forma de abordar el proceso investigativo: la combinación de la indagación artística y académica, además del desafío de entrar en el mundo del teatro. He desarrollado un camino en el campo de la música y tuve algunas oportunidades de acercarme al teatro musical, pero nunca había experimentado la forma y la técnica particular que trabaja Patricia Orantes, en la que los personajes, los textos y las intenciones se desarrollan de forma muy detallada, con un manejo profundo de los perfiles emocionales, psicológicos y sociales de los personajes, desde motivaciones, conflictos y objetivos muy específicos.

Desde la perspectiva de la sociología del cuerpo planteada por Loïc Wacquant (2004) y la relación entre arte y resiliencia propuesta por Boris Cyrulnik (2007), elaboré la argumentación teórica para adentrarme en este proceso. El viaje por estos nuevos terrenos inició con la parte de improvisación, la generación de materiales como base para la dramaturgia y el acondicionamiento corporal; asimismo, se llevó a cabo el aprendizaje de las reglas del teatro y del escenario de mi parte. Posteriormente, fueron naciendo los personajes, sus perfiles, sus formas de relación, la dramaturgia y, finalmente en 2019, se llevó a cabo una temporada de 11 funciones, en las cuales también se indagó la percepción del público asistente mediante una evaluación con preguntas abiertas.

Para esta investigación, se planteó como objetivo general profundizar en las particularidades del proceso creativo teatral desde la perspectiva de la propia corporeidad y la experiencia como bases de indagación. Los objetivos específicos fueron:

2 Patricia Orantes es una destacada actriz y directora teatral con más de 30 años de carrera. Su trabajo se centra en la construcción de personajes desde la integralidad y profundización en aspectos históricos, psicológicos y emocionales, que son las bases fundamentales para que los mismos se expresen y cobren vida.

ESCENA. Revista de las artes, 2021, Vol. 81, Núm. 1 (julio-diciembre), pp. 465-494 
a. Generar un proceso dramatúrgico autobiográfico de un monólogo que explore el devenir de las relaciones de género desde la década de 1950 hasta la actualidad en la ciudad de Guatemala.

b. Explorar el proceso investigativo desde la propia creación teatral como herramienta epistemológica y metodológica en la profundización del análisis de una etnografía propia.

c. Visibilizar en el monólogo las violencias sutiles que enfrenta la sociedad guatemalteca, especialmente las mujeres.

d. Indagar en la percepción del público sobre la obra y los elementos relevantes de las reacciones ante la puesta en escena.

Los objetivos anteriores se plantearon en torno a la siguiente pregunta de investigación: ¿de qué manera la experiencia creativa teatral que atraviesa el cuerpo puede constituirse en fuente generadora de conocimiento y construcción de memoria histórica? A continuación, se presentan los pilares teóricos desde los cuales se basó el estudio.

\section{Cuerpo y alma, las raíces del proceso creativo: aproximación teórica}

\section{a. Un conocimiento que atraviesa el cuerpo}

El sociólogo Loïc Wacquant, en su búsqueda por comprender las dinámicas sociales en las comunidades afroamericanas en Estados Unidos, se acercó a los gimnasios de entrenamiento de box, donde tanto entrenadores como aprendices eran afroamericanos. En el desarrollo de sus indagaciones, terminó por inscribirse en uno de estos gimnasios y vivir en carne propia el riguroso proceso de entrenamiento. A partir de esta experiencia que trasciende la observación y se centra en la propia vivencia de la realidad en estudio, se percató de una nueva forma de generar conocimiento, en la cual dicha experiencia atraviesa el cuerpo y, con ello, se aprehende la realidad estudiada, pues se descubren profundos entramados de significados que no se comprenderían con una observación a distancia.

Como investigadora en el proceso artístico creativo, estos planteamientos de Wacquant (2004) fueron un pilar importante que me permitieron reflexionar sobre la propia experiencia de crear e interpretar una obra teatral, puesto que también fue una vivencia que me atravesó en carne propia y trascendió la observación externa de procesos creativos con artistas de esta disciplina que había realizado en estudios anteriores. Es así cómo el proceso fue una puerta que abrió posibilidades de crear nuevas vías de indagación y de aporte a la investigación cualitativa al entrar a la creación teatral como herramienta para elaborar una 
etnografía desde la memoria relacionada con las subjetividades de las mujeres en la ciudad de Guatemala, al contrastar las experiencias de mitad del siglo XX con las realidades actuales, confrontadas con mi propio cuerpo inmerso en el viaje de la creación teatral.

Wacquant (2004) sostiene que el adentrarse no solamente con una observación participante, sino realmente vivir la cotidianeidad en inmersión profunda con quienes habitan un espacio y condiciones sociales determinadas, genera la internalización y apropiación de esquemas cognitivos, estéticos, éticos y conductuales en dicha cotidianeidad. Enfatiza que se aprende a partir del cuerpo, en el cual está inscrito el orden social y, a partir del él, se viven constantes confrontaciones con el entorno y, también, se construyen subjetividades y afectividades. De ese modo, según el autor, se hace necesario sumergirse en las complejidades in situ, no solo racionalmente, sino que el investigador necesita involucrar todo su cuerpo, su sensibilidad y una inteligencia encarnada en el centro mismo de las fuerzas simbólicas que intenta comprender; dejarse poseer, de alguna manera, por ese mundo al que entra y con el que le unen diversos lazos. Así, defiende el valor de lo que denomina "una sociología carnal", la necesidad de dejarse transformar por la experiencia, la necesidad de realizar una investigación que parta desde el cuerpo, al que considera como herramienta misma de indagación y como fuente de construcción de conocimiento. También, el autor enfatiza en la importancia de la inmersión en la praxis social, que considera intensamente corpórea, en la forma en que la cultura existe, se adquiere y se transmite en un universo kinestésico, una consciencia encarnada, en una combinación de tres elementos: el cuerpo, la consciencia individual y la consciencia colectiva.

Desde esta perspectiva, existe una yuxtaposición de un análisis sociológico, una profundización etnográfica que permiten comprender la realidad conceptual y la percepción desde los sujetos, ya que se descubre, a partir de las experiencias vividas -tanto los factores externos como las sensaciones internas-, las representaciones sociales desde las cuales se construyen mundos particulares. En este sentido, el cuerpo se constituye como base, instrumento y objetivo al mismo tiempo y, a través del mismo, se pueden comprender las diversas lógicas de la praxis social, donde existe una relación circular entre los aspectos individuales y colectivos.

A partir del cuerpo se rompe la frontera entre la razón y los aspectos afectivos, entre la acción y la representación. Todo ello adquiere sentido al profundizar en el contexto en que se dan las dinámicas sociales, las interacciones y las formas en que los sujetos se adaptan a sus circunstancias de vida. Según Wacqant (2004), solamente se pueden comprender los 
significados de un colectivo social de forma completa al establecer relaciones con la estructura de oportunidades de vida de los sujetos que ofrece o niega el sistema social. Además de ello, es importante indagar en la forma en que los lugares adquieren un valor simbólico, a veces ritual o sagrado, y en la manera en que las interacciones y las acciones que se dan en los mismos también adquieren un carácter ritual. En otra línea, se adquiere un fuerte sentido de pertenencia al compartir experiencias intensas con otros y objetivos comunes. Este sentido de pertenencia adquiere pleno significado en relación con la estructura de oportunidades de vida que ofrece o niega el sistema social inmediato.

En la praxis, en este caso del deporte del box, pero que se puede aplicar perfectamente a la praxis de la creación artística y de la puesta en escena, la acción encarnada se vuelve el centro; la consciencia discursiva y reflexiva no tienen un rol tan preponderante como la acción misma. De hecho, existen momentos en que lo racional se pierde para entrar en otro tipo de consciencia. La acción y su evaluación se fusionan y este no es el momento para la parte reflexiva, sino que se trata de un momento de total inmersión en un universo determinado para poder aprehenderlo y experimentar los momentos y los símbolos que lo constituyen. Solamente de esta manera puede llegar a entenderse lo que no se puede transmitir con palabras, sino a través de la vivencia de un complejo entramado de posturas, gestos físicos, formas de interacción y la huella que deja la acción en los cuerpos. La estructura de la realidad que se vive, habitúa y remodela los cuerpos según sus normas tácitas y sus exigencias. Así existe un dominio práctico de esquemas fundamentales, que quedan grabados en dichos cuerpos a partir de la continua repetición de las acciones.

Tanto en el box como en el montaje teatral, el cuerpo es moldeado a partir de la constante repetición de pequeños movimientos, los detalles se trabajan de manera muy minuciosa, así como las posturas corporales a partir de los perfiles psicológicos y emocionales de los personajes. A partir de la constante repetición y trabajo interno, se crean memorias corporales que quedan instaladas al momento de la interpretación y la puesta en escena. Además de ello, existe la exigencia de implicar todos los sentidos en una intensa vivencia del momento presente, de escuchar con todos los sentidos, de modo que cada escena, por más que se haya repetido muchas veces, sea como la primera vez que se experimenta.

Para Wacqant (2004), las emociones tienen tres elementos constitutivos: el gesto, la experiencia consciente y los procesos fisiológicos, los cuales funcionan como un sistema. Si uno de ellos se ve afectado, la emoción tiene modificaciones. Más que abundar en la parte racional, hay momentos en que el instinto tiene un rol más importante. Al respecto, dentro 
de la dinámica del entrenamiento, se crea un conocimiento colectivo donde existen jerarquías implícitas, que funcionan como diversas formas de aprender de los otros aun cuando no exista la intención consciente de enseñar. Esto también puede verse en el mundo de las artes escénicas, donde existe una forma de espejearse frente a quienes acompañan el proceso creativo, pues hay diversas vías de mutuo aprendizaje, formas de respeto del espacio, de relación entre los cuerpos, el manejo del tiempo y el ritmo interno de la obra.

A partir de la praxis, se crea un tipo particular de pedagogía que trasciende las palabras. La acción en sí misma devela los símbolos del universo de la disciplina que se vive y experimenta en carne propia, sus valores, los objetivos, incluso una forma de inculcar la humildad, pues en lugar de hacer alarde de las habilidades, lo que se pretende es hacer eficientes las acciones y los movimientos. Lo mismo sucede en el mundo del teatro a partir de la idea de la "economía de movimiento"3.

\section{b. La creación del relato, la historización}

Un aspecto importante del proceso creativo de esta obra, al tratarse de un tema autobiográfico, fue reconstruir la historia de las mujeres de mi familia a partir de mis propios recuerdos en imágenes fragmentadas, experiencias vividas con ellas, conversaciones con mi madre y otros miembros de la familia. Asimismo, fue fundamental investigar el contexto social, económico y político de la ciudad de Guatemala en la época en que se plantean los personajes. Fue una práctica que Cyrulnik (2007) denomina "historización". El autor sostiene que, cuando el dolor es muy intenso, es necesario tomar un poco de distancia para superarlo. Aquí tiene un papel muy importante la representación "apenas podemos convertirlo en representación teatral, la desdicha se hace soportable, o más bien la memoria de la desdicha se metamorfosea en risa o en obra de arte" (Cyrulnic, 2007, p. 14). De tal manera, existe una gran importancia en la construcción del relato a partir de una experiencia dolorosa. Con este proceso, se le da sentido al sufrimiento y también una comprensión de cómo se pudo superar una desgracia. Asimismo, Cyrulnik (2007) indica que toda persona herida se ve forzada a realizar una metamorfosis en su ser.

3 Es un estudio profundo y detallado sobre la manera de lograr acciones y transiciones con la mínima cantidad de movimiento posible, haciéndolos eficientes, fluidos y limpios. Esta fue una constante observación de Patricia Orantes durante el proceso de montaje de la obra La Casa.

ESCENA. Revista de las artes, 2021, Vol. 81, Núm. 1 (julio-diciembre), pp. 465-494 
Es decir, mediante la elaboración del relato, la persona que ha sufrido el trauma construye una identidad narrativa, un espacio en el que puede controlar la narración de la desgracia sufrida. El reto es transformar la memoria de lo vivido en una obra de arte. El teatro, el relato y la reflexión son procesos para re-trabajar las emociones. Son también una posibilidad para crear mundos imaginados y situaciones ideales. Los hechos adquieren sentido a partir de que podemos volverlos un relato. Cyrulnic explica cómo la construcción del relato contribuye a la superación de las crisis y a la reinserción a la sociedad de quienes las han vivido. Lo describe así:

El medio más eficaz y finalmente bastante rápido de resocializarlos es la metamorfosis del traumatismo. Desde el instante en que se puede hablar del traumatismo, dibujarlo, ponerlo en escena, pensarlo, se domina la emoción que en el momento del impacto se desbordaba en nosotros o que nos dejaba helados. Es en la representación de la tragedia que se reorganiza el sentimiento provocado por el estrépito (Cyrulnik, 2007, p. 67).

Desde las reflexiones del autor, se comprende que el arte permite de alguna manera sublimar la tragedia. El humor también es una forma valiosa de defensa y la representación de lo acontecido a partir de un profundo dolor; permite tomar distancia, situarse desde la postura de un observador de la propia vida y, de cierta forma, moldear la realidad y comprenderla desde diversas perspectivas. El relato da pie a la construcción de una identidad autobiográfica, desde la cual se construye un sentimiento de coherencia y de aceptación; una reflexión sobre el pasado, iluminada desde el presente. De igual manera, es necesario que el relato sea escuchado por alguien, ya que esto contribuye a una formación de identidad. El compartir el relato cumple una función de cohesión: se establece una relación de empatía y aceptación cuando vemos que el otro está dispuesto a escuchar nuestra historia. Aun cuando no ha compartido los mismos acontecimientos, se establece un lazo de confianza y, con ello, se crea una historia común. Así, la construcción del relato y de las identidades narrativas juegan un papel muy importante para que la sociedad pueda asumir los hechos traumáticos que surgieron en su seno. El vivir en una cultura que niega, juzga y no mira a las víctimas, hace que se conviertan en víctimas por segunda vez. Son personas rechazadas por una cultura que les impide superar el trauma, luego de haberlas salvado. Siguiendo a Cyrulnik (2007), se puede afirmar que toda cultura se ve tentada a negar la historia:

Cuando la realidad es incómoda, contribuimos a la denegación social. ... al revés de una denegación emocional, el dominio de la memoria es un signo totalitario 
... para que la teoría sea coherente hay que amordazar las informaciones que obligan a cambiar la teoría. El orden reina en la representación. Lo real está en otra parte (Cyrulnik, 2007, p. 32).

En tal sentido, el autor explica que la sociedad tiende a rechazar los hechos de terror como un mecanismo de defensa, es decir, ignorara los testimonios crudos. Cuando estos hechos se convierten en una narración, se construye un puente y se abren puertas, dado que, de esta forma, es más fácil poderlos asumir y manejar. Es así que se genera un proceso de historización y vías para que la sociedad pueda sanar. Este es un punto vital que surge desde el arte para regenerar los tejidos sociales. Por lo tanto, desde esta perspectiva, puede verse que la creación artística es una vía de construcción de memoria histórica y una herramienta fundamental para la transformación social y cultural, un camino necesario para la regeneración de sociedades que, en su seno, generaron procesos de traumas culturales que dañaron profundamente a sus miembros.

\section{c. Los micro machismos}

El teatro como una vía para develar las múltiples violencias que viven las mujeres ha sido ampliamente trabajado en Guatemala por colectivos como "Las Poderosas", que ha generado herramientas creativas, de reflexión y de formación respecto a temas de género, específicamente sobre la toma de conciencia de las experiencias vividas por víctimas de violencia doméstica. También hay experiencias de teatro comunitario como las llevadas a cabo en la región de Santa María de Jesús, en el departamento de Sacatepéquez. Asimismo, procesos individuales como la propuesta de Regina José Galindo que, desde hace más de dos décadas, ha marcado un importante referente del performance como vía para la visibilización y denuncia de hechos violentos que, incluso, son responsabilidad del Estado como el acaecido el 8 de marzo de 2017 en el "Hogar Seguro Virgen de la Asunción", institución pública cuyo fin era proteger a niños, niñas y adolescentes, en el cual, por negligencia de las autoridades, murieron 41 niñas calcinadas. Como se ha mencionado con anterioridad, el objeto de este proceso de investigación, más que generar avances en el propio terreno teatral, tema en el que han realizado valiosos aportes las experiencias citadas, fue generar nuevas vías en la investigación cualitativa tradicional, al situar la experiencia creativa teatral como herramienta metodológica para indagar profundamente en las subjetividades y en las construcciones simbólicas de la cultura. Por tratarse de un monólogo, cuyo eje conductor fue poner la mirada sobre las violencias que pasan desapercibidas, se hace referencia a los 
denominados micro machismos como un concepto desde el cual pueden explicarse las actitudes y prácticas que refuerzan el sistema patriarcal en una sociedad como la guatemalteca, las cuales son normalizadas y mantenidas en los diversos sectores sociales.

Ferrer, Bosch, Navarro, Ramis y Esther (2007) sostienen que los micro machismos son formas solapadas de la manifestación de violencias que se dan generalmente en el ámbito privado, las cuales se constituyen en delitos ocultos, dado que no son evidentes. Son acciones perpetradas mediante un ejercicio desigual de poder, principalmente a través de ataques sutiles prolongados de orden psicológico o sexual dentro de estructuras sociales patriarcales que los normalizan. Generalmente, la víctima no es consciente de tales ataques y desconoce sus derechos. Además, el concepto se refiere a "aquellas conductas sutiles y cotidianas que constituyen estrategias de control y microviolencias que atentan contra la autonomía personal de las mujeres y que suelen ser invisibles o, incluso, estar perfectamente legitimadas por el entorno social” (Ferrer, et al., 2007, p. 342). Estas acciones se dan con el objetivo de mantener, reafirmar o recuperar el dominio sobre la mujer o frenar su poder personal y autonomía.

Desde este concepto, se aborda el hilo temático conductor del monólogo La Casa con la vivencia de estas violencias sutiles desde la experiencia de cuatro mujeres en la ciudad de Guatemala, dos de ellas nacidas en este territorio, quienes a pesar de ser hermanas afrontan su realidad de manera muy distinta, ambas fueron jóvenes en la década de 1950. Marina tiene la posibilidad de estudiar y es de las primeras químicas biólogas graduadas de la universidad pública; ella enfrenta la realidad de tener que legitimarse constantemente frente al cuestionamiento de su capacidad por parte de catedráticos y compañeros estudiantes. También, debe afrontar las constantes preguntas de su grupo social acerca de su falta de voluntad de cumplir con convenciones sociales como el matrimonio. Consuelo, su hermana, no puede estudiar por una enfermedad que la ha acompañado toda la vida y se encarga de las tareas domésticas, las cuales no son reconocidas como trabajo por su familia, incluyendo a Marina, lo cual demuestra que de forma inconsciente también las mujeres reproducimos actitudes que corresponden a los micromachismos porque estamos inmersas en ese orden patriarcal infundido desde la infancia que se refuerza en los imaginarios sociales. Ambas son tías paternas del personaje central.

Asimismo, en el monólogo cobra vida Mutti, abuela materna del personaje central, quien emigra de Alemania al final de la Segunda Guerra Mundial y se casa con un guatemalteco que luego la abandona. Ella decide quedarse en Guatemala y enfrenta el estigma de 
ese entonces: ser mujer divorciada. Con mucho esfuerzo saca adelante a sus hijos e hijas. Finalmente, Magdi, el personaje central, encarna a una mujer que vive su cuarta década en la actualidad. Es la primera de sus generaciones que empieza a cuestionarse sobre esas violencias sutiles, a romper esos patrones aprendidos y reproducidos, a luchar por su propia autonomía. Todo ello, a partir de una revisión de la historia de las mujeres pertenecientes a mi familia y llevarlas a mi propio cuerpo, me permitió -como actriz y como investigadoragenerar ciclos constantes de revisión histórica, construcción de memoria, sistematización de experiencias no solo desde un orden racional, sino a partir del cuerpo, el trabajo del perfil emocional y psicológico de los personajes, el desplazamiento en el espacio, la escritura de la dramaturgia y, posteriormente, un diálogo con el público.

\section{d. El teatro autobiográfico, la familia y el relato de la verdad}

Un desafío de la creación del monólogo La Casa fue la reconstrucción histórica de la vida de los personajes, sobre todo en los momentos de vacío en los que se carecía de información. Acordamos con Patricia Orantes, directora de la obra, hacer una mezcla entre realidad y ficción; el relato se construyó a partir de datos verídicos, un análisis del contexto social de la época y la imaginación. Esto es permitido en el mundo teatral y ha sido analizado por autores como Julie Ann Ward (2013), quien sostiene que, en el ámbito teatral, existe una mezcla, a veces una tensión entre ficción y realidad. La autora enfatiza que la asociación entre el teatro y lo imaginativo está profundamente arraigada, a pesar de que muchas veces el público tiene la expectativa de que un teatro autobiográfico debe responder totalmente a hechos históricos o, en contraste, no tiene ninguna relación vital con el contexto sociohistórico narrado en la obra.

Cuando el monólogo fue presentado, como se describe más adelante en el presente artículo, a pesar de que el público era en su mayoría jóvenes que no conocieron de primera mano la realidad de las mujeres de mediados del siglo XX, sí se identificaron con las violencias sutiles que aún persisten en las actuales generaciones y, a partir de la obra, pudieron analizar los signos de estas prácticas en mujeres de sus propias familias. En este sentido, Ward (2013) también hace importantes planteamientos sobre el caso específico de representar historias familiares en el terreno teatral. Dado que el pertenecer a una familia conlleva intrínsecamente una herencia ideológica, una visión de mundo específica, el relato teatral permite tanto el análisis y deconstrucción de esas formas de pensamiento traducidas en ideas y formas de actuar, como el establecimiento de los límites individuales frente al clan. 
Además, el teatro se convierte en un puente entre el mundo de los vivos y los muertos. A veces el ámbito de la representación y el relato son la única forma de tener una relación con los ausentes. Es así que la creación teatral permite profundas formas de interrelación y de dar voz a quienes han trascendido, lo cual genera una nueva vía para la construcción de memoria histórica.

A partir de las propuestas teóricas anteriores, se abordó el análisis del proceso creativo que concluyó en la creación y presentación en escena del monólogo titulado La Casa, una obra autobiográfica que recoge momentos claves de la vida de mujeres de mi familia paterna, materna y la mía propia, atravesadas por el hilo conductor de las micro violencias de género y también por las estrategias de resiliencia desarrolladas para superar las crisis y fortalecerse en nuevas visiones de ser, comprender y enfrentar la realidad. Iniciamos el proceso creativo a finales de 2017, fue un trabajo minucioso que inició con ejercicios de escritura, para posteriormente pasar a la escena a dar vida a los personajes. Hubo algunos momentos de interrupción del trabajo por otras obras que se estaban trabajando dentro del Laboratorio Teatral de la Universidad Rafael Landívar, pero retomamos en 2018 para llegar al estreno en septiembre de 2019.

El título del monólogo está relacionado con que el momento creativo coincidió con que yo estaba a cargo de vender la vivienda en la que transcurrió mi infancia y los primeros años de juventud. La había comprado mi abuelo a principios del siglo XX, por lo que yo soy la tercera generación que vivió en ese lugar. Al ser la responsable de decidir qué hacer con el inmueble, tuve fuertes emociones encontradas y recuerdos que emergían de las memorias en cada rincón. Ese fue el contexto en el que se empezó a gestar la obra. Los personajes surgieron de la vida real de mujeres en mi familia que dejaron profundas huellas en mí. En seguida hago una breve descripción de cada una.

La tía Marina: una de las primeras profesionales en química biológica en Guatemala. Vivió su juventud en la década de 1950, época de la denominada "primavera democrática en Guatemala", con el gobierno de Jacobo Arbenz que marcó un ciclo de apertura y desarrollo integral que fue interrumpido abruptamente con su derrocamiento en 1954. Marina participaba de los grupos de juventud universitaria, siempre defendió su autonomía y el amor por su profesión. Era defensora de los derechos de la mujer, aunque no abiertamente feminista.

La tía Consuelo: hermana de Marina, dos años mayor. Tuvo poliomelitis y una salud frágil desde pequeña. Su condición física la obligó a mantenerse en casa. Contrario a Marina, 
era más tímida e introspectiva, era el espíritu que cohesionaba a toda la familia. No tuvo la posibilidad de ir a la universidad. Ellas dos, Marina y Consuelo, eran mis tías paternas.

Mutti: mi abuela materna. Nació y creció en Alemania, de niña vivió la Primera Guerra Mundial y, en su juventud, cuando contrajo nupcias con mi abuelo, diplomático guatemalteco en Alemania, estaba la Segunda Guerra Mundial en su momento más álgido. Cuando Guatemala se unió a los aliados y declaró la guerra a Alemania, todos los diplomáticos de esta nacionalidad tuvieron que salir de ese país. Mi abuela vino a Guatemala en 1942 con mi madre recién nacida. Posteriormente, se quedó sola con cuatro hijos y logró sacarlos adelante con mucho esfuerzo.

Magdi: soy yo misma en dos momentos: mi infancia y adultez. Este personaje es el hilo conductor y viaja por la obra en el ámbito del recuerdo, la construcción de memoria y en el presente mediante la expresión de manifiestos personales en torno a las violencias invisibles, las mal llamadas "micro violencias" que atravesaron a las mujeres que la antecedieron y a ella misma. Cuestiono esta denominación, puesto que estas manifestaciones de ejercicio de poder, que son sutiles y, a veces, invisibles, atentan igual que las violencias manifiestas contra la vida física, emocional y psicológica de las víctimas. Es decir, no son pequeñas, sino que se trata de acciones y estrategias perpetradas progresivamente y que, en ocasiones, quienes las sufren pueden correr riesgos muy grandes puesto que, al no ser claramente visibles, tienen menor oportunidad de encontrar apoyo en personas cercanas o instituciones del Estado.

He realizado esta breve descripción de los personajes para contextualizar la obra. A continuación, puntualizo los elementos principales de la investigación y del proceso creativo.

\section{El camino metodológico}

Como comenté anteriormente, esta investigación tiene como antecedente un estudio de observación directa sobre el proceso creativo en la gestación de obras artísticas por parte de colectivos en teatro, danza y artes visuales. En seguimiento a ello, inicialmente planteé que el involucrarme y ser yo misma la que creara e interpretara un monólogo iba a ser metodológicamente una forma de observación participante. En el proceso me percaté que el trabajo trascendía por mucho esta forma de acercarse al fenómeno de estudio porque cuando se hace observación participante, a pesar de formar parte de la realidad que se investiga en actividades o procesos puntuales, el objetivo es nunca perder la consciencia de 
que el fenómeno se está observando; es decir, tener siempre presente que es algo externo que se está observando aun cuando se participe de la celebración, de la fiesta, de la actividad específica de un colectivo social.

En este caso, el estar tan involucrada, mediante la prestación mi cuerpo para dar vida a los personajes y la vivencia de las intensas emocionalidades, me exigía entregar todas las áreas que me componen: las racionales, las físicas, las psicológicas y las emocionales, estar totalmente imbuida en el momento presente, por lo cual no podía tener esa consciencia de meta observación y desligarme del proceso para no perder de vista lo que estaba observando. Este camino metodológico fue una construcción de conocimiento a partir de la experiencia que atraviesa no solo el cuerpo, sino todo el ser. Es así que la creación artística permite abrir nuevos caminos metodológicos en el ámbito investigativo, dejarse atravesar por la realidad, construir memoria y elaborar nuevas visiones de la misma a partir de la creación, la corporeidad, la significación de los espacios y de los objetos, la voz.

La obra misma es una forma de conclusión de un ciclo, la concreción de una realidad que se ha transformado a nivel interno y que abre puentes de diálogo con quienes la presencian. Con el proceso pude experimentar en carne propia los planteamientos teóricos de Löic Wacqant (2004) cuando expresa que, solamente al imbuirse totalmente en una realidad, puede comprenderse en sus complejidades y en sus profundos significados. La investigación también estuvo acompañada por la elaboración de un diario de campo donde recogí las vivencias desde el inicio hasta el final del proceso. Al concluir las funciones, realicé una entrevista a profundidad con la directora de la obra, Patricia Orantes, con el fin de profundizar en su análisis del trabajo desde la perspectiva de la dirección teatral. Por último, vale resaltar que durante el ciclo de presentación, que tuvo un total de 11 funciones, se entregó al público asistente un breve cuestionario para recoger sus percepciones. En total se tuvo la respuesta de 292 asistentes.

\section{El proceso creativo}

La primera gran decisión fue escoger si tomar el camino autobiográfico o la ficción. Patricia Orantes, en su labor de dirección, hizo mucho énfasis en la importancia de la elección porque lo autobiográfico es exponer niveles muy profundos tanto de la memoria, no solo personal, sino de familiares cercanas en este caso, como una constante confrontación emocional profunda. Es exponer al mundo la propia vida. 
Dado que la memoria es fragmentaria, siempre existen pequeños elementos de ficción que surgen de la investigación de historias de vida, del contexto en que ocurrieron los hechos y, a partir de estos procesos de indagación, se incluyen inferencias de cómo pudieron acaecer los sucesos que quedan en el vacío. Este también es un elemento muy valioso para la construcción del hilo conductor de la memoria.

No dudé en que fuera autobiográfico, parecía que la obra misma lo demandaba así, también las circunstancias de la venta de la casa, desprenderme de ella, influyeron. Parecía que las mujeres de mi familia querían hablar a través de mí y yo tenía una profunda necesidad en ahondar y superar la despedida de ese lugar tan significativo durante tres generaciones. El crear una obra teatral desde la historia propia y de mujeres de mi familia fue un proceso de confrontación constante desde la toma de los personajes y escribir lo que deseaban expresar hasta la puesta en escena; construir una memoria que me trasciende. No es solo una historia personal, son hechos que se tejen con otras mujeres incluso situadas a grandes distancias geográficas porque las violencias nos han atravesado a todas y también la construcción de estrategias que defienden la vida y motores que trascienden las crisis.

En este aspecto, el proceso creativo teatral tiene similitud con la herramienta etnográfica de la historia de vida, que se construye justamente a partir de la experiencia vital de una persona, relacionada con el contexto sociohistórico más amplio. Un aspecto curioso es que dentro de los personajes principales apareció la tía Consuelo, que murió cuando yo tenía un año de edad, tengo de ella muy vagas imágenes, pero seguramente ella marcó una impronta muy fuerte que quedó grabada en mi subconsciente.

Iniciamos el proceso ubicando las edades en las que los personajes aparecerían en la obra, los saltos de tiempo en cada uno de ellos y el contexto social y político de la época en que se ubicaron. Marina y Consuelo aparecen en varios momentos de su juventud y adultez. Mutti se encuentra en los últimos momentos de vida antes de morir y Magdi tiene dos momentos: uno en su infancia y otro en su edad adulta.

Inicié con numerosos ejercicios de escritura previo a crear los textos de los personajes. Fueron prácticas para crear el idiolecto, es decir, la forma característica y cotidiana de expresarse, sus frases distintivas, también qué les gustaba y les disgustaba, lo que amaban y odiaban. En este tema, Patricia Orantes insistió en que en mi escritura dejara emerger la forma incorrecta en que se habla en lo cotidiano, el lenguaje coloquial. Sostenía siempre que así somos los humanos, incorrectos y que allí radicaba la fuerza de los personajes. 
Mi escritura, al principio, era muy descriptiva y quizá poética, por lo que, en su labor de dirección, ella insistió en que dejara tanto la narrativa para adentrarme en lo concreto de la realidad que vivían los personajes y centrarme más en la acción, porque el teatro es movimiento. Entonces, en lugar de explicar tanto, la idea era generar acciones, imágenes que tuvieran un profundo significado.

Hice textos de presentación de cada personaje: su historia de vida desde la infancia, una descripción de cómo era su carácter y de forma muy importante cuáles eran sus conflictos. Según Orantes, el conflicto es el motor de la acción dramática, por lo que era necesario situarlas en un momento conflictivo ${ }^{4}$. El teatro, al igual que el proceso investigativo científico, se centra en la identificación de un problema, en la profundización de sus matices y en aportar soluciones desde las distintas perspectivas de sus personajes. Es así como, a partir de ese nudo de conflicto que puede darse entre personajes, de un personaje con sus circunstancias externas o procesos psicológico-emocionales internos, se generan los matices de la obra. Tal y como explica José de Santos,

la esencia de lo dramático estará conformada, pues, no por hechos normales y cotidianos de la vida reproducidos en escena, sino por elementos puestos en conflicto que den lugar a una acción, y que esta, por su naturaleza, despierte una respuesta emocional en el personaje -y en el espectador-. Esa acción, que provoca el conflicto, será la responsable de canalizar y mostrar el enfrentamiento entre las partes en pugna de la trama (De Santos, 2002, p. 7).

Luego de esta primera etapa de ejercicios de escritura, nos tomamos un tiempo para reflexionar algunos aspectos importantes desde la teoría dramática: los tipos de conflicto, el gran objetivo de la obra, los objetivos de los personajes y los míos como actriz. Asimismo, se llevó a cabo la creación de los subtextos que son la especificación de la intención desde la cual el personaje expresa sus parlamentos. Me parece muy interesante este aspecto porque los subtextos son como una obra paralela que el público nunca presenciará directamente, pero que intuirá porque definen el motor emocional, psicológico, incluso, político desde el que el personaje emite sus mensajes.

4 Entrevista realizada a Patricia Orantes, el 17 de octubre de 2019. Consideré importante hacer una entrevista a la directora del monólogo La Casa para enriquecer la memoria de la sucesión de las diferentes etapas del proceso creativo y para conocer su perspectiva del trabajo como directora y la forma en que ella vivió el proceso.

ESCENA. Revista de las artes, 2021, Vol. 81, Núm. 1 (julio-diciembre), pp. 465-494 
Posteriormente, inició la etapa de improvisación, de ir a la escena. Recuerdo que esto me hacía sentir muy confrontada emocionalmente. Aunque he trabajado varios años en la música y en el canto, esta es otra forma muy distinta de entrar al espacio del escenario. Me sentía más cómoda escribiendo que improvisando, esto era un reto para salir de mi zona de confort. Algunos de los ejercicios de improvisación consistieron en situar a un personaje determinado en una situación de conflicto y, desde allí inventar, cómo lo vivía, cómo reaccionaba, cuáles eran sus luchas. En otros momentos, Patricia Orantes le hacía una especie de entrevista al personaje, le dirigía varias preguntas y yo, como actriz, improvisaba las respuestas. Trabajamos mucho el tránsito en el espacio del escenario. Inventar en el momento hacía que emergieran memorias que guardaba en mi subconsciente de la relación con cada una de las mujeres que iba a interpretar. De estos ejercicios, surgió una segunda fase de escritura donde ya se fueron concretando los parlamentos. Aparecieron otros personajes ausentes en escena a quienes las diferentes mujeres presentes evocaban o a quienes les hablaban. Algunos personajes también transitorios y muy pequeños, que también se trabajaron.

Se incluyeron algunos textos que denominamos pronunciamientos, los cuales corresponden a tres momentos en la obra en los cuales yo presento mi postura personal frente a las llamadas "micro violencias". Estos están distribuidos en momentos específicos e importantes al inicio, en el medio y, al final, de la obra. Además, elaboré una tabla donde especificaba la relación entre los personajes presentes y ausentes, si su relación era filial y si era de unión o aversión. A continuación, presento un ejemplo de las relaciones de Marina.

Tabla 1. Ejemplo de relaciones entre personajes y sus emocionalidades.

\begin{tabular}{|c|c|c|c|}
\hline Personaje presente & Personaje ausente & Tipo de relación & Emocionalidad \\
\hline Marina & Esteban & No filial- novio & $\begin{array}{c}\text { Amor, duelo } \\
\text { de despedida. }\end{array}$ \\
\hline Marina & Consuelo & Filial-hermana & $\begin{array}{c}\text { Amor, es su pilar } \\
\text { de vida. }\end{array}$ \\
\hline Marina & Jorge & Filial-hermano & $\begin{array}{c}\text { Amor, conflicto, } \\
\text { rivalidad. }\end{array}$ \\
\hline Marina & Manuel & Filial-padre & $\begin{array}{c}\text { Amor, } \\
\text { agradecimiento, } \\
\text { admiración. }\end{array}$ \\
\hline
\end{tabular}

ESCENA. Revista de las artes, 2021, Vol. 81, Núm. 1 (julio-diciembre), pp. 465-494 


\begin{tabular}{|c|c|c|c|}
\hline Personaje presente & Personaje ausente & Tipo de relación & Emocionalidad \\
\hline Marina & Magdalena & Filial-madre & $\begin{array}{c}\text { Amor, } \\
\text { duelo por muerte. }\end{array}$ \\
\hline Marina & Mimita & Filial-abuela & $\begin{array}{c}\text { Amor, nostalgia, } \\
\text { duelo }\end{array}$ \\
\hline Marina & Mugdi & Filial-sobrina & $\begin{array}{c}\text { Amor, protección, } \\
\text { proyección de } \\
\text { su vida en ella. }\end{array}$ \\
\hline Marina & $\begin{array}{c}\text { No filial-madre } \\
\text { de la esposa de } \\
\text { su hermano }\end{array}$ & $\begin{array}{c}\text { Aprecio, tolerancia, } \\
\text { conflicto. }\end{array}$ \\
\hline
\end{tabular}

Fuente: elaboración propia.

Se hizo una tabla como la anterior para cada uno de los personajes. Luego de la segunda fase de escritura, cuando decidimos qué parlamentos tendría cada personaje, Patricia Orantes propuso una escaleta, es decir el esqueleto de la sucesión de hechos en la obra, desde el principio al fin. Esta propuesta fue dialogada entre ambas, de manera que yo también propuse algunos cambios hasta que consensuamos todo el recorrido de la obra. Esta es la escaleta que ordenó la secuencia del monólogo:

\section{Escaleta de La casa}

- LA DESPEDIDA: ella está en la casa a punto de cerrarla y despedirse para siempre del lugar. Ha terminado de empacar las cosas que quedan, objetos de sus tías, de su padre y de la abuela. Su ex pareja la llama insistentemente, ella no quiere responder y lo hace finalmente ante la insistencia. Ella sabe que, cerrando la casa, también cerrará una historia de opresiones.

- LA INVOCACIÓN: vuelve a su infancia y juega con las sombras, con las estrellas dibujadas en las baldosas que se convierten en galaxias, en microbios y en escenarios. Cuando sea grande, mi voz alcanzará toda esta sala. Grita tanto que se encuentra con su tía Marina que le habla del microscopio y las bacterias. Marina le habla y descubre a lo lejos a Mutti. Comenta sobre ella y Consue.

- CONSUELO: Consue adulta, luego se va a la infancia.

- PRONUNCIAMIENTO UNO: escena del presente. Reacción ante las violencias sutiles. 
Algo la hace volver al pasado. Recuerda a Mutti.

- EL FÉNIX: escena de Mutti a punto de morir.

- PRONUNCIAMIENTO DOS: reacción ante la crítica externa y defensa de las apariencias.

- AGRADECIMIENTO: escena de Marina con el padre.

- VALENTÍA: Marina le cuenta su episodio de amor y la decisión de quedarse sola (transición).

- PRONUNCIAMIENTO TRES: regreso al presente. Definición de límites, rompimiento.

- ELLAS EN Mí: agradecimiento a ellas, canto.

Fuente: elaboración propia con ayuda de Patricia Orantes.

Patricia Orantes sostiene que el nacimiento de esta obra fue un poco caótico porque viajamos entre la escritura y la improvisación, entre el trabajo en escena y las lecturas reflexivas en las que se corregían, acortaban o se modificaban textos. Al reflexionar sobre ello, veo que hubo un orden subconsciente, una danza entre los distintos elementos y no un trabajo lineal que pudiera haberse concebido como orden, en el sentido estricto y tradicional de la palabra. El ir y venir, como la vida misma, permitió hilar fino cada parlamento de los personajes, las manifestaciones de violencia y la resiliencia como hilo conductor, los conflictos, los objetivos tanto de los personajes como míos como actriz, las intenciones y los subtextos.

Luego de todo el trabajo previo, el montaje de las escenas fluyó rápidamente. Al inicio se tuvo la idea de hacer una escenografía con una pared llena de cajas que pudieran ser movibles y así crear espacios específicos para las escenas. Al final se decidió optar por la menor cantidad de objetos posibles, los que estuvieron en escena eran propiedad de las mujeres que aparecían en la obra, de mis tías y mi abuela, míos, objetos propios de la casa. Fue una escenografía minimalista. Fue interesante, también, partir de cierta precariedad, porque no se tenía mucho presupuesto destinado para el montaje, como sucede muchas veces en nuestros contextos latinoamericanos. Sin embargo, esa misma precariedad nos hizo reflexionar sobre lo que era realmente importante mostrar en escena y que los objetos presentes tuvieran una fuerte carga simbólica. Es así cómo creamos un montaje con cero presupuesto, en el que se le dio un protagonismo muy importante al diseño de luces para fortalecer las emocionalidades y marcar los territorios de las escenas.

Para finalizar este apartado, cabe señalar que uno de los aspectos más importantes como vía creativa y de construcción de memoria fue el cuerpo. Los ensayos fueron muy intensos, en numerosas ocasiones me sentía totalmente agotada, tanto por la intensidad 
emocional como por la exigencia de atención plena, la repetición continua de los mínimos detalles: cómo dar un paso, cómo colocar los pies, que no se pierda el personaje y su voz característica, que esta voz surja de un espacio natural y no se oiga caricaturizada, darle profundidad a la intención. Otro aspecto relevante fue la claridad de tener consciencia de lo que Patricia Orantes denomina los vectores, es decir, el enfoque de la dirección de la mirada, especialmente, cuando como actriz me dirigía a personajes ausentes. Fue importante tener clara la ubicación de estos en el espacio y, cuando me movía de lugar, volver a ver exactamente al lugar en donde los había situado visualmente con anterioridad.

\section{Tránsitos por los territorios: el cuerpo y los espacios}

El trabajo desde el cuerpo jugó un papel fundamental en todas las etapas del proceso creativo y, claro está, en la puesta en escena. Siempre desde la labor de dirección, Orantes insistió en que el teatro más que narrativa, es acción, movimiento. De ese modo, para introyectar a los personajes, hubo un intenso trabajo a partir de la combinación de imágenes y mi cuerpo. Uno de los ejercicios iniciales fue imaginar frente a mí a cada personaje, observar en mi mente, como si los tuviera enfrente, cómo era su cuerpo, su postura y luego prestar mi cuerpo para que ellos entraran simbólicamente en mí. Entonces yo iba tomando poco a poco sus posturas.

Este proceso fue muy interesante porque, al permitir que las mujeres representadas en la obra tomaran mi cuerpo, iban emergiendo memorias en mí que tenía completamente olvidadas. A partir de imágenes visuales, sensoriales, auditivas y emocionales, iba construyendo la memoria propia y de esas mujeres de mi familia, como dispositivos que se dispararon desde mi subconsciente. Creo que este es un hallazgo importante en términos investigativos para ahondar en las subjetividades individuales y colectivas, dado que se trata de una forma distinta de construcción de la historia de colectivos y territorios concretos.

Otra práctica importante fue ubicar en dónde estaba el centro motor de cada personaje, su centro de energía, ese lugar del cuerpo de donde partía su movimiento y también la base tanto de su postura como de su desplazamiento en el espacio. En el caso de Consuelo, quien tenía una pierna afectada por la poliomielitis, hicimos una investigación sobre la enfermedad y cómo es el movimiento de quienes han sufrido sus secuelas. A raíz de ello, hice un ejercicio de ponerme una piedra en el zapato para tener la sensación de molestia y experimentar con ese objeto desplazándome en el espacio; también hice uso de recursos como un bastón para que se quedara grabada la forma de desplazamiento en mi cuerpo. 
Un aspecto muy importante de establecer ese centro motor fue que de allí partía la voz peculiar del personaje. Por ejemplo, el centro motor de Marina estaba en su pecho, su voz era aguda, muy abierta, con un timbre alto. Contrario a Consuelo, cuyo centro estaba en la pierna izquierda que había sido afectada por la polio, su voz era mucho más tenue, salía de un modo más introspectivo, como desde sus entrañas. De alguna manera, corporicé la emocionalidad, el perfil psicológico, los conflictos y los objetivos de los personajes. Había ejercicios en los que desde mi mirada y todo mi cuerpo debía traducir completamente el estado interior del personaje.

Un proceso que ayudó mucho a dar vida a los personajes fue el ejercicio que Patricia Orantes denomina la galería, el cual consiste en adoptar la postura de un personaje y todo su gesto característico unos minutos para soltarlo y pasar al siguiente con rapidez sin hablar. De esta forma hacía un recorrido empezando generalmente por Marina joven, luego a Magdi (yo) niña, Magdi adulta, Consuelo adulta y finalizaba con Mutti anciana. Esta práctica era muy interesante porque en poco tiempo había que concentrar toda la atención en la energía y naturaleza de un personaje para soltarlo y luego asumir el siguiente. Esto ayudó técnicamente a construir las transiciones entre uno y otro al momento de interpretar el monólogo.

Las transiciones fueron trabajadas hasta el mínimo detalle. Orantes insistía en lo que llama economía de movimiento, concepto que consiste en lograr con la menor cantidad de movimientos posibles pasar de una acción a otra. Sostenía que existía una serie de pequeños y sutiles movimientos innecesarios que ensuciaban dichas transiciones, por lo que era necesario deshacerse de ellos para que la interpretación quedara limpia. Otra acotación era evitar reforzar con movimientos el parlamento, por ejemplo, decir "sí" y mover la cabeza en gesto afirmativo. Esto era difícil porque a veces el movimiento redundante no es intencional.

Asimismo, me indicó que no me tomara tanto tiempo en pasar de un personaje a otro, pero que le diera intensidad a la energía y al estar antes de tomar el siguiente. Esto me generaba mucha confusión porque no sabía cómo lograrlo; era un desafío reducir al máximo los movimientos, entrar en la intensidad del personaje, lograr estar, terminar una acción con la energía arriba, no tomarme tanto tiempo en la transición y entrar con otra emocionalidad totalmente distinta al siguiente personaje. Escudriñamos milimétricamente cada movimiento, lo que Orantes llamaba bordar cada mínimo detalle de la escena hasta que me indicó que había tenido el hallazgo para lograr una transición limpia: era partir de un movimiento del que naciera el cambio hacia el siguiente personaje (un movimiento de cabeza, la mirada hacia otro lado, un cambio en la posición de los pies) y quedarme congelada en la última 
acción, como en una foto, para dar paso al siguiente. Con ese estudio minucioso de los movimientos y lograr hacer solamente los que fueran necesarios, logramos la limpieza en los cambios de personaje a personaje. Este proceso fue una deconstrucción de la cotidianeidad a través del movimiento, porque esas dinámicas de la vida cotidiana fueron diseccionadas en imágenes de micro acciones para generar, de nuevo, un movimiento fluido que apelara a la vida en el día a día de los personajes.

Me percaté, también, de que el retener mentalmente las acotaciones dadas por la dirección y memorizar el texto era mucho más fácil cuando estaba en escena, a partir del movimiento mismo. Fue una dinámica diferente porque anteriormente hubiera pensado en que tenía la necesidad de anotar todo, pero a partir de la corporeidad pude aprender nuevas formas de retención de información y ejercicio memorístico. Existe otro tipo de memoria que se despierta a partir del trabajo corporal. Fue muy interesante en este caso que el proceso implicara encarnar fragmentos de la vida de mujeres que me antecedían, ya que de cierta forma se despertaba una memoria genética. Como bien acotaba Patricia Orantes, ellas viven en mi cabello, en mis huesos, en mi piel. En este punto, pude evidenciar los planteamientos de Wacquant (2004), descritos anteriormente, en el sentido de que al involucrar el cuerpo en una experiencia y en un contexto determinados, al sumergirse en una situación, se construyen nuevas formas comprender la realidad y crear memoria histórica.

En una escena del monólogo se incluyó una secuencia de imágenes que cruzaban el texto y el movimiento corporal. Por ejemplo, hay un momento en que el personaje de Magdi dice: "están tan calientes mis entrañas", lo asocié con los momentos en que tengo migraña y siento que se calienta mi cabeza, por lo que apretaba mi cabeza con las manos al decir ese texto. Otro correspondía a una ironía, cuando una de las voces de la crítica decía "debieras ser como tu mamá, tan dulce, tan servicial” y la sensación era de aprisionamiento, entonces apretaba mis brazos con mucha fuerza al expresarlo.

Hubo intensas emocionalidades que se despertaban a partir de una postura corporal, las cuales iban ligadas a la tensión que ponía en mi cuerpo y al seguimiento de las acotaciones que Patricia Orantes me daba desde la dirección. Por ejemplo, me pidió condensar al máximo posible el estado de la muerte, el momento de la agonía. Trabajamos para lograr encarnar la emoción y situarla en cada parte de mi cuerpo, desde el cabello hasta los dedos de los pies en su máxima intensidad. No podía pasar a la siguiente acción hasta sentir completamente este estado. Así fue también con momentos de enojo e indignación, que estuvieron apoyados por memorias de mi vida que llevaba a la escena. La postura genera- 
Imagen 1. Secuencia de transiciones entre personajes.

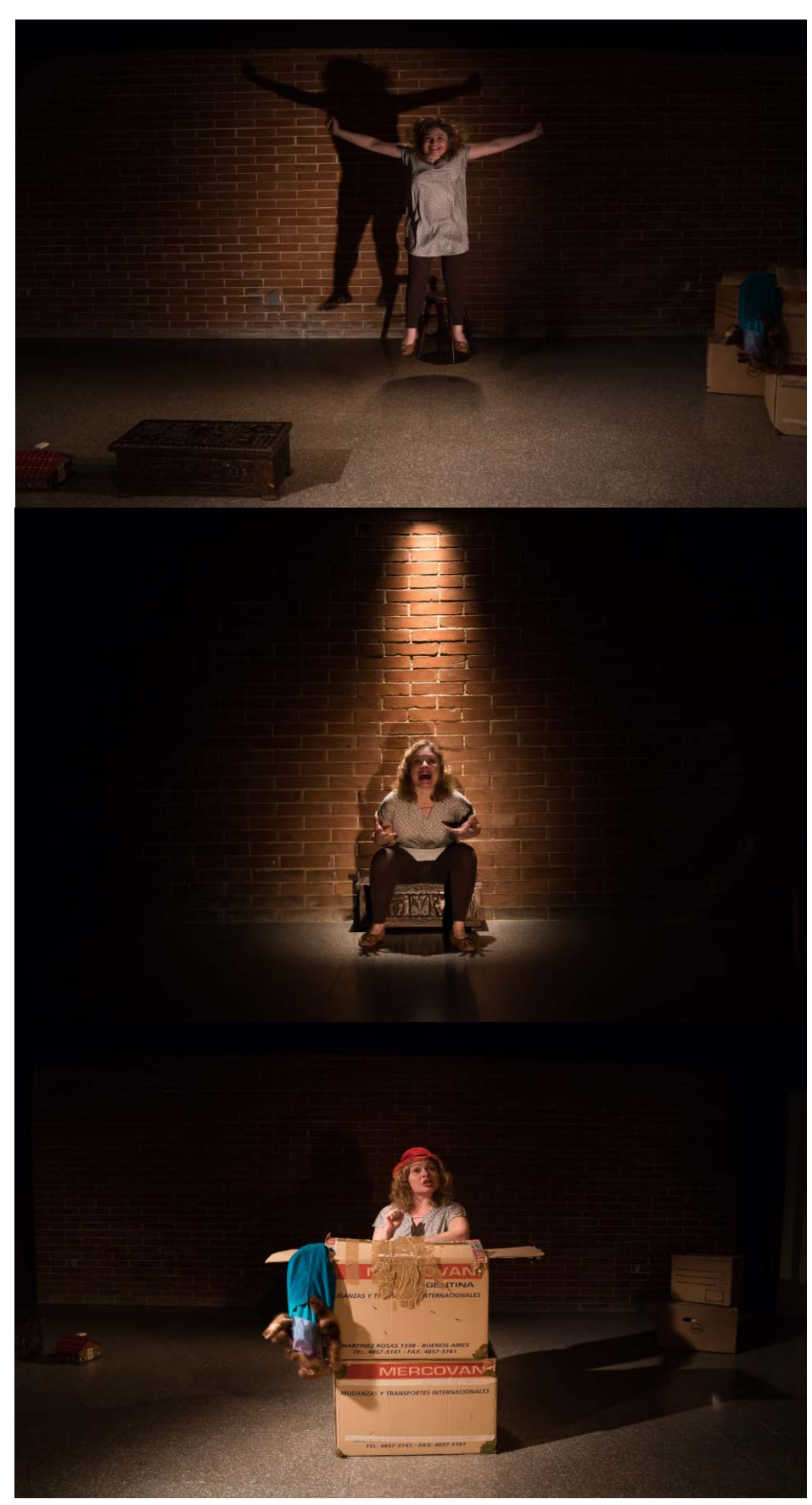

Fuente: Archivo fotográfico de la Universidad Rafael Landívar. Autor: César Ubieto. ba sensaciones emocionales más extremas como ponerme en posición fetal en el piso, apretando al máximo mis brazos y piernas, por lo que mi pecho quedaba atrapado haciendo más dificultosa la respiración. En el momento en que el estado emocional llegaba a su máxima intensidad, podía decir el texto. En esa línea, el contacto directo de la mirada con el público también fue importante, ya que decidimos romper la cuarta pared, esa barrera visual con el público, para entrar a un acercamiento emocional a través de lanzar preguntas directas a personas que presenciaban la obra.

A partir de toda esta experiencia me percaté de la vulnerabilidad en que los actores y actrices se encuentran en momentos clave del montaje, ya que si es un trabajo a profundidad, exponen lo más profundo de sus emociones. En este sentido, hay una relación de poder entre quien dirige y quien actúa, ya que quien ejerce la labor de dirección tiene ante sí toda una vulnerabilidad que manejar y conducir. Patricia Orantes siempre tuvo sumo cuidado en ese aspecto y siempre me insistía en que nada debía lastimarme, que se trataba 
de llevar las emociones al máximo, pero que esto no debía afectarme. De allí, también la práctica constante de entrar al estado, pero también soltarlo.

\section{Relación con el espacio y los objetos, el mundo del significado y el ritual}

Tanto el espacio como la relación con los objetos están cargados de profundo significado y hasta un aspecto ritual en el teatro. Me parecía muy interesante que, en cada ensayo, Patricia Orantes me pedía reflexionar un momento sobre la razón por la que yo estaba allí ese día y sobre cómo me sentía emocional, física y mentalmente. Solo en el momento en el que tenía clara la razón, podía entrar al espacio del escenario. Posteriormente, empezaba a caminar y a reconocer todo el espacio, a relacionarme energéticamente con el mismo. Cuando se montaron las escenas, cada personaje tenía su propio territorio. Consuelo en una esquina que denominamos el rincón de Consue, Marina más hacia el centro del escenario, Mutti en la parte central pero más atrás. Magdi en sus diferentes etapas tenía más libertad de movimiento.

La decisión sobre los objetos en escena, el planteamiento de la división de los espacios a partir de situaciones vitales, emocionales y psicológicas de los personajes respondió a una forma de condensar simbólicamente tanto su propia situación de vida como la experiencia de muchas mujeres en la sociedad guatemalteca que viven realidades similares. En este sentido, puede decirse que las obras artísticas son registros materiales de la cultura y de la historia. Al respecto, Geertz (2003) plantea que la cultura no es solamente un conjunto de rasgos, sino un entramado profundo de significados que orientan el actuar humano. Tanto la cultura como la historia son procesos en constante cambio y transformación, no son elementos estáticos. De esta cuenta, las obras artísticas y el teatro en particular son un registro que sintetiza y muestra al mundo esa construcción simbólica; al crearse a partir de inmersiones profundas en la complejidad humana, son un reflejo dinámico de los imaginarios sociales, las crisis, los cuestionamientos y las rupturas que se generan en un territorio y contextos sociales específicos. Desde la dirección siempre se me daba la indicación de que antes de entrar al ensayo me despojara de todo objeto que no fuera neutro: aretes, anillos, incluso tenía que cambiarme de ropa para transformar mi energía hacia un estado de apertura para los personajes.

La obra iniciaba con el personaje de Magdi escribiendo en un cuaderno. A medida que avanzaron los ensayos y durante la temporada de presentaciones, iba escribiendo cada vez más y el cuaderno se cargaba de un significado mayor. Incluso, Orantes me pidió decidir 
cómo sería ese cuaderno al momento en que Magdi lo tomaba: si ya estaba escrito, si era la primera página en blanco. Decía que es algo que el público nunca sabría, pero cargaría de significado las acciones, así como las bases de los subtextos, los objetivos y los conflictos.

Como mencioné con anterioridad, todos los objetos que estuvieron en escena eran de mi propiedad o de alguna de las mujeres de mi familia presentadas en la obra. Hubo varios ejercicios en los que la directora me pedía relacionarme profundamente con cada uno de ellos e, incluso, hacerles una historia de quién los habría fabricado, cómo era esa persona, cuándo se adquirió, cómo fueron usados, entre otros. Ella era meticulosa con cada detalle y decía que el teatro es de cierta forma un ritual para traer al presente a los que ya partieron. De esta cuenta, dedicamos un buen tiempo a tomar cada objeto: una pequeña casa de madera, el cuaderno, un cofre, un álbum de fotos, un celular, sombreros, un vestido y entrar en una profunda relación con cada uno de ellos. A partir de esto, elaboré una tabla de la relación entre personajes y objetos que presento a continuación.

\section{Tabla 2. Relación de personajes y objetos}

\begin{tabular}{|l|l|}
\hline \multicolumn{1}{|c|}{ Personaje } & \multicolumn{1}{c|}{ Objeto } \\
\hline Magdi & Casa \\
\hline Magdi & Cuaderno y lapicero \\
\hline Magdi & Celular \\
\hline Magdi & Cofre y la casa \\
\hline Magdi niña & Bicho \\
\hline Marina & Cofre, libro, álbum \\
\hline Marina-padre & Poema Luz Méndez \\
\hline Marina-padre & Álbum, foto de la familia \\
\hline Consuelo & Espejo \\
\hline Consuelo & Su pierna \\
\hline Mutti & Salón \\
\hline Mutti & Jarrón \\
\hline
\end{tabular}




\begin{tabular}{|l|l|}
\hline \multicolumn{1}{|c|}{ Personaje } & \multicolumn{1}{c|}{ Objeto } \\
\hline Mutti & Las olas \\
\hline Magdi & Sombrero blanco, alusión a Marina \\
\hline Marina & Sombrero blanco \\
\hline Marina & Sombrero rojo, cajas \\
\hline Marina & Sombrero de exploradora \\
\hline Marina & Sombrero negro \\
\hline Magdi & Sombrero negro \\
\hline Magdi & Cajas, cofre, banco \\
\hline Magdi & Casa \\
\hline
\end{tabular}

Fuente: elaboración propia.

Imagen 2. Objetos como condensadores de significado.

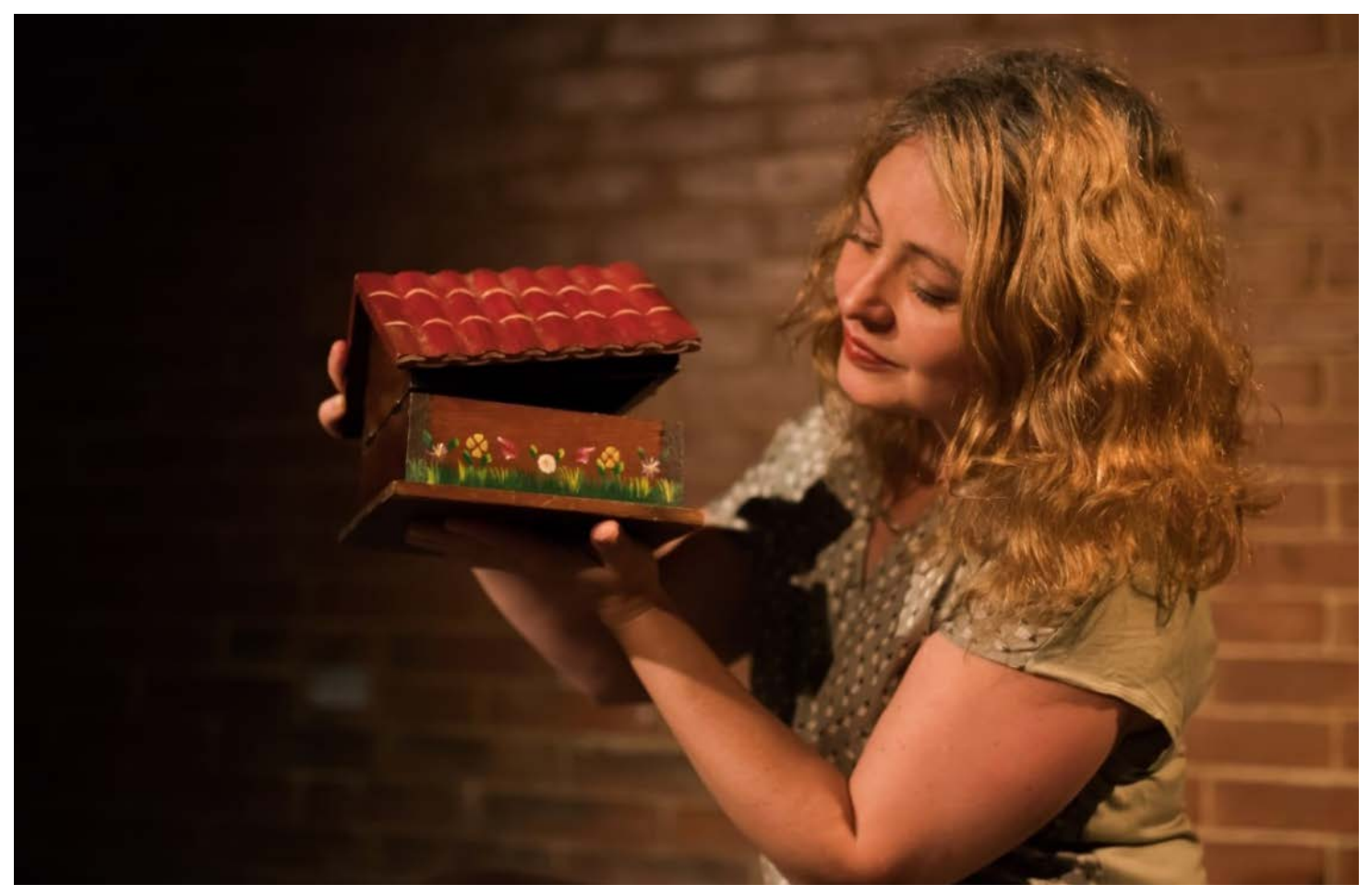

Fuente: Archivo fotográfico de la Universidad Rafael Landívar. Autor: César Ubieto. 
A pesar de que el público no se enteró de este trabajo de relación con lo simbólico de cada objeto, varias personas que presenciaron la obra sí notaron que dichos objetos eran reales, que provenían de las realidades que se estaban representando y preguntaron sobre ello en los foros posteriores a las funciones. Este trabajo de conexión con los objetos, la construcción de sus historias y su estudio a detalle generó una fortaleza en el simbolismo de los mismos en escena.

\section{Percepción, el espejo del público}

Al concluir cada función del monólogo, cuya temporada fue de 11 funciones en septiembre y octubre de 2019, se abrió un espacio de diálogo con el público asistente y también se aplicó un cuestionario de preguntas abiertas para recoger las percepciones y reacción ante la obra. El cuestionario fue llenado por 292 asistentes.

En estos diálogos posteriores, a pesar de que en la obra se presentaron problemáticas que atañen a mujeres desde la mitad del siglo XX, hasta generaciones actuales en edad adulta, las y los jóvenes asistentes coincidieron en que las manifestaciones de diferentes tipos de violencia en el ámbito familiar y social, no solo las explícitas, sino las que se dan de forma sutil y casi invisible, son situaciones que no se han superado y que siguen vigentes. Coincidieron en que es importante visibilizar y cuestionar las conductas que se normalizan e, incluso, se promueven porque las llamadas "micro violencias" son tan sutiles que se consideran normales e incluso son reforzadas a través de distintos discursos, publicidad, valores religiosos, las instituciones, entre otros.

Dentro de las emociones que despertó la obra, el público citó tristeza, nostalgia, enojo, miedo, dolor, impotencia e inconformidad ante el pensamiento tan conservador que prevalece en la sociedad guatemalteca. En contraste a ello, también se mencionaron la esperanza de sanar y de romper paradigmas, el amor propio y los procesos de confrontación para trascender el dolor.

Mujeres de distintas edades que presenciaron la obra expresaron que sentían reflejadas sus propias historias de vida en la obra y que esto era "como medicina" para ellas y una oportunidad que también a ellas les permitía sanar. Mientras que algunos jóvenes manifestaron que no se habían percatado de la situación hasta ver la obra y que esto les hizo hacer memoria de vivencias relacionadas con el tema en su familia, además de tomar consciencia de esas manifestaciones violentas sobre todo hacia las mujeres y también su fortaleza y capacidad de resiliencia. Una observación constante que me hicieron fue sobre mi valentía 
al plantear estas historias propias y familiares, lo cual denota que aún en la actualidad estos temas son poco discutidos, sino ignorados en nuestros contextos sociales guatemaltecos.

Me impactó mucho que, al finalizar las funciones, el público se quedaba un espacio de tiempo en silencio y hasta después aplaudía, había una especie de respeto o de reflexión ante lo presenciado. De igual manera, la audiencia valoró los espacios en los que yo estaba en silencio, en los que solamente trabajaba la mirada, la economía de movimiento y la condensación de emociones. Dentro de los aspectos que impactaron al público, expresaron que, en el aspecto técnico, la transición y el cambio de los personajes era algo que les llamó mucho la atención, el adoptar personalidades muy distintas en momentos cortos. Hubo personas que pensaban que la violencia se manifiesta solamente en el ámbito físico y no se habían percatado de sus diversas formas sutiles hasta presenciar la obra.

Expresaron, también, que el teatro es una herramienta importante para mostrar realidades crudas de una manera no tan cruel, es decir, más fácil para el público de asumir y reflexionar. Asimismo, se mencionó que es una vía para manifestar lo que nos han hecho callar, un instrumento que permite sanar, reconstruir la historia, generar cambios y formas de liberación sin ser juzgados; que es importante llevar a cabo procesos teatrales que partan de la investigación de la realidad. Finalmente, valoraron que el teatro permite un abordaje de las realidades involucrando todos los sentidos, lo cual permite un impacto mayor, huna huella que permite abrir otras perspectivas.

\section{Conclusiones}

Al finalizar esta experiencia de escribir, encarnar y escenificar un monólogo de corte autobiográfico, uno de los hallazgos más importantes es la vivencia de que el dolor puede ser transmutado, dado que el terreno de la representación teatral permite no solo abrir y cerrar ciclos emocionales, sino dar un nuevo sentido a las experiencias dolorosas que al compartirse permiten generar vías de sanación colectiva. A partir de prestar mi cuerpo a la obra, se abrieron nuevas formas de despertar la memoria propia y de las mujeres de mi familia que formaron parte del monólogo. Una memoria que no reside solamente en el ámbito racional, sino que involucra aspectos genéticos, emocionales, psicológicos y afectivos. Podría decir que es una memoria integral que toca la profundidad humana en su totalidad, al tratarse de un proceso de una etnografía propia que ahonda en los entramados simbólicos de la vida, la cultura y el contexto sociohistórico.

ESCENA. Revista de las artes, 2021, Vol. 81, Núm. 1 (julio-diciembre), pp. 465-494 
Es un proceso muy intenso y a veces agotador, pero también sanador de forma individual y colectiva porque las experiencias de las realidades planteadas se tejen con otras historias en mi contexto social. El teatro y las artes en general son una representación de momentos que surgen en un espacio y tiempo determinados y de problemáticas que los trascienden y se repiten en las nuevas generaciones. Quizá el arte no resuelva todas las situaciones macro, pero trabaja ámbitos muy profundos y sutiles. Después de una experiencia como la que viví, hay reflexiones que no se hubieran dado mediante otro proceso de corte racional o solo verbal. Hay aspectos que cambian para siempre y nuevas preguntas que nacen a partir del trabajo creativo.

De ese modo, la creación teatral y los procesos creativos artísticos en general son una herramienta muy importante para la construcción de conocimiento, de la memoria y de la historia. Aunque la memoria autobiográfica es fragmentaria, el proceso de investigación en los contextos sociales en que se dieron los hechos y el contraste con documentación, permite una reconstrucción más fidedigna de dicha historia. En ese sentido, la elaboración de un relato autobiográfico es un espejo de una historia más amplia, ya que el presentar una experiencia íntima o de un núcleo pequeño permite generar lazos con quienes lo presencian en cuanto a vivencias y contextos comunes, reflexionar sobre el pasado y el presente para poder generar pasos hacia la transformación social. El relato se vuelve un puente entre la realidad cruda y la sociedad, permite superar el choque de los acontecimientos traumáticos con una elaboración artística, lo cual abre puentes de diálogo entre distintos sectores sociales.

En los aspectos técnico y metodológico, el trabajar una experiencia desde lo que se describió como la sociología encarnada en los planteamientos de Waqcant (2004), descritos al inicio de este artículo, develó que la experiencia que atraviesa el ser permite comprender los fenómenos no solo desde el orden racional, sino que involucra aspectos profundos de las subjetividades, las emociones, lo psicológico y las formas de relacionarse consigo mismo y con quienes comparten un colectivo social. El proceso creativo teatral es un riguroso trabajo investigativo que incluye desde el planteamiento de preguntas, objetivos, indagaciones etnográficas, indagaciones en los contextos socio-históricos, hasta aspectos particulares como una deconstrucción del movimiento cotidiano a detalle, el cuerpo como sujeto y objeto mismo de estudio, los territorios del escenario, el lenguaje cotidiano. Todo ello genera una confrontación profunda con la realidad. Más que una representación es una praxis social, el accionar de dicha realidad, una búsqueda constante en lo cotidiano desde su lenguaje hasta las formas de intersubjetividad. 
A partir de las primeras etapas de improvisación creativa, hay un contacto con el subconsciente que permite traer a la superficie tanto aspectos de la memoria como imágenes sensoriales que emergen por dispositivos de la realidad que las hacen emerger. De allí que haya un círculo continuo de relación entre el mundo interno de quien actúa o elabora la dramaturgia con los estímulos externos de la realidad que le toca vivir.

Durante la presentación de la temporada, pudo evidenciarse, a través del diálogo del público perteneciente a las nuevas generaciones, que la práctica de los micromachismos en Guatemala no ha cambiado. A pesar de que progresivamente las mujeres se abren espacios en ámbitos sociales, laborales, políticos, entre otros, estas prácticas de manifestación sutil y solapada de la violencia siguen manifestándose, dado que, en el ámbito social, han cambiado de forma, pero en el fondo sigue prevaleciendo ese orden patriarcal profundamente enraizado en la cultura, que se normaliza a través de las instituciones sociales.

Desde la base del análisis de percepción con el público que presenció la obra La Casa, pudo constatarse que la misma despertó una toma de consciencia de las problemáticas referentes a la violencia de género, específicamente a sus manifestaciones sutiles. Miembros de la audiencia se percataron que la vivían o que se experimentaba en su entorno cercano y, ante ello, cuestionarse e, incluso, según sus palabras, sanarse, al ver que estas situaciones no se viven de forma aislada. Por lo tanto, el teatro es una vía para la regeneración de los tejidos sociales a nivel profundo e integral en los seres humanos.

\section{Referencias}

Cyrulnik, B. (2007). La maravilla del dolor. El sentido de la resiliencia. Argentina: Granica.

De Santos, J. (2002). La estructura dramática. Las puertas del drama, 10, 4-9.

Ferrer, V.; Bosch, E.; Navarro, C.; Ramis, C. \& Esther, G. (2008). Los micromachismos o microviolencias en la relación de pareja. Una aproximación empírica. Anales de Psicología, 24 (2), 341-352.

Geertz, C. (2003). La interpretación de las culturas. España: Gedisa.

Wacquant, L. (2004). Body and Soul. Notebooks of an apprentice boxer. New York: Oxford University Press.

Ward, J. (2013). Self, esteemed: Contemporary Auto/biographical Theatre in Latin America. Berkeley: Universidad de California.

ESCENA. Revista de las artes, 2021, Vol. 81, Núm. 1 (julio-diciembre), pp. 465-494 